\title{
PENINGKATAN KINERJA SISTEM PROPULSI KAPAL PENANGKAP IKAN TRADISIONAL TYPE PURSEINE 30 SD 90 GT MENGGUNAKAN SISTIM PROPULSI HYBRID
}

\author{
Mohd Ridwan \\ Program Diploma III Teknik Perkapalan \\ Fakultas Teknik Universitas Diponegoro
}

\begin{abstract}
Mohd Ridwan, in this paper explain that traditional fishing vessels built in the shipyard of the people is a cultural heritage which needs to be conserved, and empowered through the application of ship science and technology to build fishing boats for fishermen of all types, shapes and sizes of ships, equipped with fishing technology. Repairs to the feasibility of traditional fishing vessels to sail like stability, ship construction needs to be done. Similarly, his case should be applied to ship propulsion technology that remained operational needs based on size of vessel forms and types of fishing vessels. The design of an appropriate propulsion can provide benefits in the form of operational cost savings by more than $10 \%$ through the use of hybrid propulsion systems. Hybrid propulsion system is a mix of main engine (motor fuel or gas fuel MDO) with electric motor and propeller to suit the use of hull form and ship propulsion systems (matching the propeller and engine) is at the core of this concept in this article and next to be research. Besides these traditional ship the product to be supported primarily by imposing government standards for a fishing vessel, for fishermen as users can easily calculate the economic value of investment will they planted in fishing effort at sea.
\end{abstract}

Keywords : Fishing Boat Traditional, Hybrid Propulsion, Main Engine, Propeller, Operatinal Cost.

\section{LATAR BELAKANG}

Kapal ikan tradisional, merupakan sarana penangkapan ikan di laut yang digunakan masyarakat nelayan pantai utara pulau Jawa. Jenis kapal penangkap ikan yang banyak dijumpai adalah type Pursein.

Kebijakan pemerintah dalam menentukan: Jenis kapal, ukuran kapal, propulsi, permesinan kapal dan jenis alat tangkap (fishing gear) untuk suatu area penangkapan ikan, harus dikelola sedemikian rupa agar jumlah armada yang dioperasikan dapat memberikan manfaat pada para nelayan, serta tidak menimbulkan over fishing yang akan menghambat usaha penangkapan ikan di laut.

Kecendrungan harga bahan bakar yang terus meningkat, menyebabkan biaya operasinal sekali melaut semakin tinggi, karena komponen pembiayaan terbesar pada kapal penangkap ikan adalah pemakaian bahan bakar $\pm 40 \%$. Sehingga kondisi ini menjadi kendala dalam usaha penangkapan ikan di laut terutama bagi nelayan yang memiliki modal terbatas.

Masyarakat nelayan sebagai pelaku usaha penangkapan ikan dengan berbagai usaha lain pendukungnya, di Indonesia masih memiliki tingkat pendidikan yang relatif rendah dibandingkan masyarakat lain, namun memiliki sifat yang sangat dinamis yaitu dapat menerima masukan, baik terhadap ilmu pengetahuan dan teknologi perikanan tangkap dan berbagai hal yang menyangkut usaha penangkapan berkelanjutan (usaha penangkapan yang mempertimbangkan jumlah tangkapan lestari) dan pemanfaatan teknologi perkapalan. Oleh sebab itu dalam hal penetapan: jumlah armada, jenis alat tangkap, dan ukuran kapal, mesin penggerak dan fasilitas kapal lain dibutuhkan kebijakan dan peran pemerintah melalui instansi terkait untuk menyusun stadarisasi kapal ikan atau kapal perikanan tangkap ini.

Kelemahan armada tangkap yang dimiliki oleh nelayan di Indonesia adalah Jumlah armada yang melakukan operasi di wilayah ZEE Indonesia sangat sedikit, hal ini disebabkan karena kapal ikan yang ada ukurannya kecil yaitu kurang dari 30 GT dengan jumlah $\pm 75 \%$ dari total unit kapal yang dimiliki nelayan Indonesia, dan sistem pembanguan kapal ikan di galangan kapal masih tradisional. Jika dilihat dari potensi ikan (6,4 juta ton/tahun, DKP 2007) maka jumlah kapal ikan, jenis dan ukuran yang tersedia tidak memadai (kontribusi perikanan terhadap PDRB rata-rata baru $3 \%$ ), sehingga hal yang paling perlu mendapat perhatian dari perikanan tangkap ini adalah :

- Penataan jenis dan jumlah kapal perikanan, alat tangkap, alat bantu penangkapan, jalur dan wilayah penangkapan.

- Penetapan standarisasi kapal perikanan sesuai dengan jenis, ukuran dan wilah tangkap.

- Penghematan penggunaan bahan bakar melalui pemanfaatan bahan bakar alternatif maupun sisitem propulsi hybrid yang merupakan perpaduan motor yang berbahan bakar disel, gas dan motor listrik.

- Peningkatan apresiasi dan partisipasi masyarakat dalam pembangunan kapal perikan melalui galangan kapal tradisional namun dengan teknologi yang terbaharu dan terstandarisasi. 
Atas alasan tersebutlah maka penelitian bidang kapal perikanan (perikanan tangkap) ini perlu dilakukan agar peran serta galangan kapal rakyat dapat meningkatkan jumlah armada kapal ikan yang layak untuk dapat mencapai ZEE Indonesia, memalui pemberdayaan dengan menerapkan ilmu pengetahuan dan teknologi perkapalan yang menyangkut masalah : konstruksi, kelayakan melaut, sistem permesinan dan propulsi yang sesuai dengan potensi perikanan dan wilayah tangkapannya.

Namun dalam kesempatan ini, konsep penelitian difokuskan pada usaha penghematan bahan bakar melalui pemanfaatan propulsi hybrid, agar ongkos operasional kapal berkurang hingga lebih dari 10\%, sehigga nelayan kembali bergairah untuk melakukan usaha penangkapan ikan di laut dan secara mikro dapat meningkatkan penghasilan masyarakat nelayan.

\section{PERUMUSAN MASALAH PERIKANAN TANGKAP}

Armada kapal ikan nelayan Indonesia memiliki keterbatasan antara lain dalam ukuran kapal (75\% berukuran kurang dari 30 GT), kemampuan jelajah, konstruksi kapal sederhana, peralatan tangkap ikan dan alat keselamatan pelayaran yang sangat terbatas, pemakaian mesin darat untuk propulsi kapal serta propeller yang tidak seimbang antara badan kapal (ukuran kapal) dengan tenaga mesin induk yang dipakai. Kemudian galangan kapal ikan yang memproduksinya tidak memiliki teknologi modren agar dapat mendesain kapal ikan yang lebih ekonomis dalam operasional penangkapan ikan.

Rendahnya ilmu pengetahuan dan teknologi yang dimiliki pihak galangan kapal, menyebabkan kemampuan produksi perikanan tangkap Indonesia sangat terbatas.

Sehingga dibutuhkan peran pemerintah untuk menetapkan standar dari seluruh komponen kapal perikanan tangkap ini, agar pihak galangan kapal tradisinal dapat langsung membangun kapal yang layak dan memiliki nilai ekonomis tinggi.

Disamping itu penerapan standarisasi kapal perikanan tangkap, juga dapat di jadikan acuan agar kapal dapat dijadikan alat hipotek, bagi pihak perbankan, sehingga masyarakat nelayan mendapatkan pnjaman untuk pengembangan usaha mereka, terutama dalam upaya pengadaan armada tangkap dan modal usaha perikanan lainnya.

Dalam pemakai motor berbahan bakar minyak bumi pada kapal perikanan juga berdampak terhadap kerusakan lingkungan dimana gas buang sebagai hasil pembakaran bahan bakar, memiliki kandungan $\mathrm{NO}_{\mathrm{x}}, \mathrm{SO}_{2}$ dan $\mathrm{CO}_{2}$ yang akan menimbulkan efek rumah kaca. Sehingga pemakaian bahan bakar konvensional ini perlu dikurangi dalam usaha perikanan tangkap.
Kecendrungan kapal ikan yang di bangun pada galangan kapal tradisional, memanfaatkan motor darat yang telah digunakan pada truk (5 tahun lebih), dan propeller yang digunakan tanpa pertimbangan terhadap efektifitas, efisiensi dan performan propeller. Sehingga hal ini meneyebabkan konsumsi bahan bakar jauh lebih boros.

\section{PEMECAHAN MASALAH}

Pememecahan masalah keterbatasan yang dimiliki kapal perikanan tangkap di atas adalah dengan menyusun standar kualitas dan kuantitas kapal ikan dan menetapkannya sebagai standar baku kapal perikanan di Indonesia.

Agar pemerintah dapat menetapkan standarisasi perikanan tangkap maka perlu dilakukan penelitian yang komprehensif terutama menyangkut:

- Jenis kapal perikanan.

- Dimensi kapal.

- Konstruksi kapal, yang berhubungan dengan : kekuatan bahan konstruksi (jenis kayu dan non kayu), bentuk dan ukuran standarnya.

- Penggerak utama, motor induk yang digunakan memiliki standar daya mesin atau power yang cukup berdasarkan kebutuhan kecepatan dari masing-masing jenis kapal dan kondisi lingkungan areal penangkapan (fishing ground).

- Peralatan penunjang (fishing gears), merupakan kelengkapan standar minimal berdasarkan jenis kapal.

- $\quad$ Perlengkapan navigasi, standar minimal untuk kelayakan navigasi kapal ikan.

- $\quad$ Standarisasi penerangan di kapal.

- $\quad$ Stadarisasi palkah ikan dengan perlengkapan atau fasilitas yang harus dimiliki pada palkah kapal ikan.

- Standarisasi tata ruang di kapal ikan (general arrangement) sehingga layak bagi ABK dan Nelayan dapat bekerja dengan baik, sesuai dengan jenis kapal.

- $\quad$ Standarisasi propulsi kapal termasuk desain propeller yang cocok dengan mesin induk.

- $\quad$ Standarisasi propulsi alternatif yang bertujuan untuk penghematan bahan bakar, termasuk : besaran power, susunan dan desain propellernya.

- Standarisasi kelengkapan administrasi kapal penangkap ikan.

- Serta standar perlengkapan penangkapan lainnya, seperti: echo sounder, GPS, dll.

Dalam hal yang menyangkut penghematan bahan bakar dapat dilakukan penelitian, terutama menyakut sistem propulsi hybrid yang merupakan alternatif pemakaian bahan bakar selain dari solar (marine diesel oil/MDO). 
Sistem propulsi dengan bahan bakar alternatif yang dipilih adalah yang memiliki kriteria sebagai berikut :

- Dampak kerusakan lingkungan minimal.

- $\quad$ Peningkatan efisiensi energi.

- Memiliki daya tahan dan ketanguhan

- Perawatan mudah.

Motor induk sebagai penggerak utama di kapal yang akan digunakan dapat berupa kombinasi antara Motor Diesel dan Motor berbahan bakar Gas (Diesel engine or gas engine) namun memiliki perlindungan terhadap kerusakan lingkungan. Motor Induk ini harus didesain memiliki efisiensi termal yang tinggi dan pemakaian bahan bakar seminimal mungkin. Motor induk juga harus memiliki daya tahan dan tanguh untuk dipakai dalam jangka waktu lama (lebih dari 5 tahun).

\section{SISTEM PROPULSI HYBRID}

Sisitem propulsi hibrid merupakan kombinasi mesin penggerak kapal, antara lain :

- diesel engine dan electric motor

- diesel engine dan gas turbine

- diesel engine dan steam turbine

- biodiesel engine dan electric motor

- fuel engine dan diesel engine

- diesel engine dan solar cel electric motor

- $\quad$ gas engine dan diesel engine, dan lain-lain

Hibrid sistem ini disamping untuk effisiensi pemakaian bahan bakar juga dapat memberikan effisiensi ruang/kamar mesin kapal.

Selain hal tersebut, energi yang dihasilkan dimanfaatkan seekonomis mungkin, seperti terlihat pada gambar 1 .

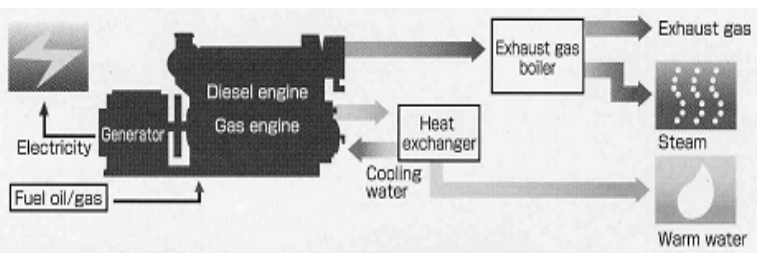

Gamba 1. Hibrid sistem gas and diesel engine

Panas yang di peroleh dari gas buang diesel engine dapat digunakan dan menghasilkan steam/uap air panas untuk kebutuhan masak, menghangatkan ruangan, sementara dari gas engine berupa air hangat, dan untuk menaikan temperatur air pendingin motor induk, alat penukar panas dalam sistem pengkondisian udara di ruang akomodasi. Dalam gambar 2. mengambarkan efisiensi pemakain energi tersebut.

Sebagian juga dapat digunakan untuk pembangkit energi listrik di kapal, saat motor induk bekerja, namun hal ini hanya dapat dilakukan maksimal 30\%.

Sistem propulsi hybrid dengan mengunakan motor listrik sebagai penggerak propeller dengan motor diesel sebagai pembangkit listrik, dapat digunakan untuk tujuan hdrodinamis propulsi ysng tinggi, seperti yang terlihat dalam gambar 3 .

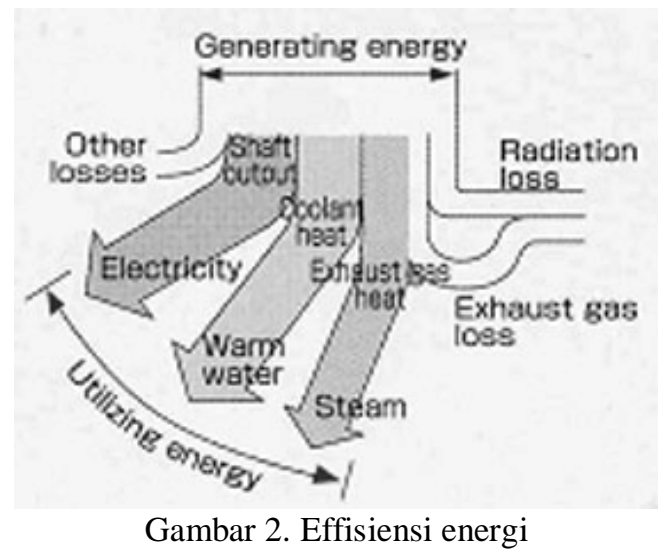

Dalam sistem tersebut menggunakan 4 unit motor diesel dengan dimensi yang kecil diabndingkan jika hanya menggunakan satu unit motor diesel sebagai penggerak utama di kapal. \$ unit motor diesel ini berfungsi sebagai pembangkit energi listrik, kemudian energi listrik ini di distribusikan untuk menggerakan 2 unit motor electric yang dikopel ke propeller menggunakan roda gigi penerus. Dan satu unit motor electric untuk menggerakan bow thruster.

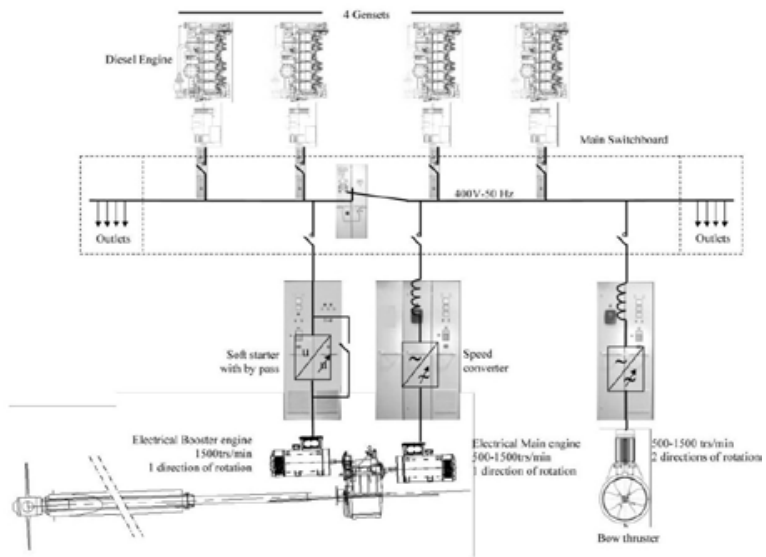

Gambar 3. Hybrid genset dan motor electric

Sistem propulsi hybrid pada gambar.4 dibawah ini adalah kombinasi penggerak utama adalah steam turbine engine, dimana steam yang diperoleh melalaui 2 unit boiler terlebih dahulu melalui motor diesel. Air tawar sebagai pendingin motor diesel masuk dengan suhu $40^{\circ} \mathrm{C}$, dan keluar dengan suhu $80^{\circ} \mathrm{C}$, kemudian air ini di salurkan ke boiler sehingga energi yang digunakan dalam boiler lebih ekonomis untuk menghasilkan steam yang di salurkan ke turbine engine. 


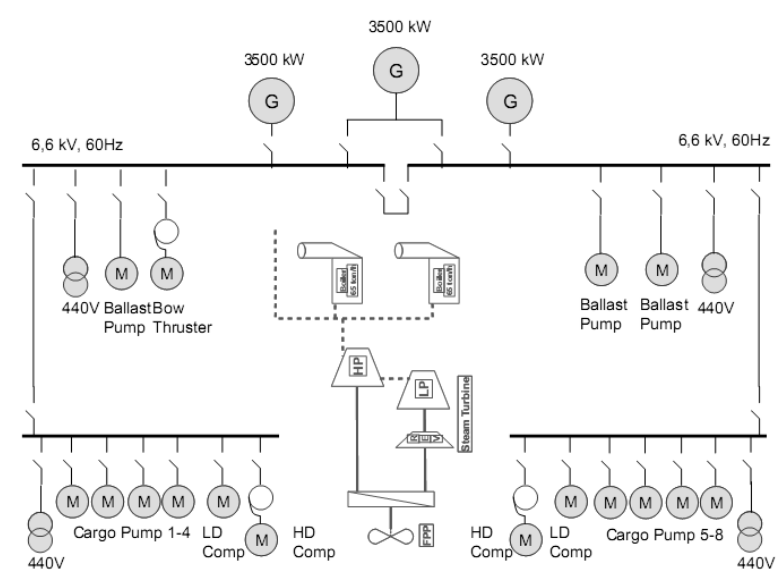

Gambar 4. Turbine gas and diesel genset

Pada gambar 5 merupakan sistem propulsi konvensional dengan 2 unit penggerak utama adalah motor diesel dua langkah (two stroake engine) dengan dimensi lebih besar dan sangat berat, dibandingkan dengan menggunakan motor penggerak elektrik. Penggerak utama langsung di hubungkan pada propeller, dengan sistem poros. Poros propeller memiliki dimensi cukup besar agar kuat untuk mentransmisikan tenaga ke propeller, karena biasanya dimensi propeller berdiameter berkisar 0,6 draft kapal, rata-rata berdimensi besar dan lebih berat. Penempatan propeller juga akan sangat terbatas di daerah buritan kapal, sehingga menyebabkan effisiensi daya dorong sangat minimal.

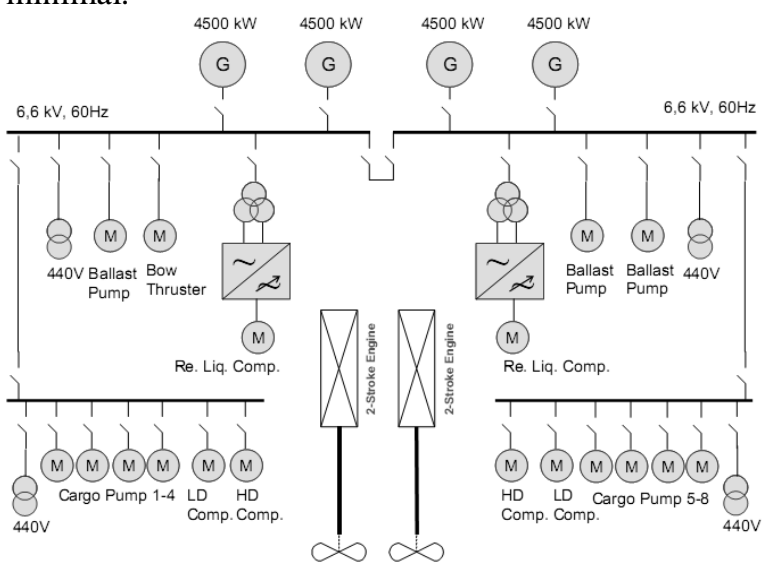

Gambar 5. Sistem propulsi konvensional

Pada gambar 6 merupakan sistem propulsi menggunakan dua unit motor elektrik sebagai penggerak utama kapal. 2 unit motor elektrik ini di gabung dlaam satu unit gearbox, kemudian baru tenaga penggerak ini di salurkan menggunakan poros propeller yang relatih lebih pendek. Penggunaaan tenaga dapat diataur dengan mudah sesuai kondisi saat kapal berlayar, di pelabuhan dan manuver, sehinggga effisiensi penggunaaan tenaga lebih tinggi, di bandingkan dengan sisitem propulsi konvensional.

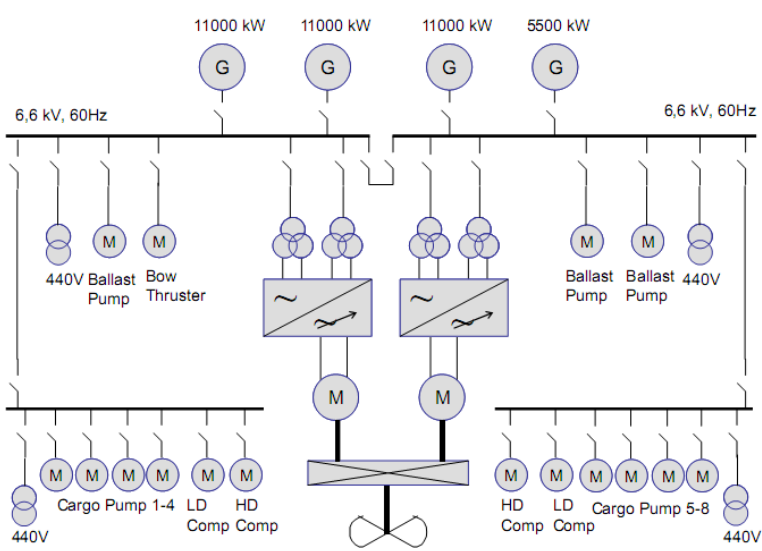

Gambar 6. Sistem propulsi motor elektrik

Perbandingan penggunaan energi dari beberapa sisitem propulsi diatas dapat dilihat dalam tabel.1. berikut.

Tabel.1. Perbandingan pemanfaatan energi (power plant) di kapal.

\begin{tabular}{|c|c|c|c|c|}
\hline Propulsion type & $\begin{array}{c}\text { Steam } \\
(\mathbf{1 4 0 K})\end{array}$ & $\begin{array}{c}\text { Dual-Fuel } \\
(\mathbf{1 5 0 K})\end{array}$ & $\begin{array}{c}\text { Two-stroke } \\
\mathbf{( 2 2 0 K})\end{array}$ & $\begin{array}{c}\text { Gas } \\
\text { Turbines }\end{array}$ \\
\hline $\begin{array}{c}\text { Total Efficiency } \\
\text { (including el. losses) }\end{array}$ & $29 \%$ & $42 \%$ & $40 \% *$ & $45 \% * *$ \\
\hline Installed el. power & $10-15 \mathrm{MW}$ & $30-40 \mathrm{MW}$ & $15-20 \mathrm{MW}$ & $45-55 \mathrm{MW}$ \\
\hline Min. voltage level & $3,3 \mathrm{kV}$ & $6,6 \mathrm{kV}$ & $6,6 \mathrm{kV}$ & $11 \mathrm{kV}$ \\
\hline Utilization (seagoing) & $15-20 \%$ & $80 \%$ & $35-45 \%$ & $70-80 \%$ \\
\hline $\begin{array}{c}\text { Utilization } \\
\text { (unloading) }\end{array}$ & $70-80 \%$ & $25 \%$ & $50-80 \%$ & $25 \%$ \\
\hline $\begin{array}{c}\text { Total installed power } \\
\text { (propulsion + aux)*** }\end{array}$ & $45 \mathrm{MW}$ & $38 \mathrm{MW}$ & $56 \mathrm{MW}$ & $50 \mathrm{MW}$ \\
\hline \\
$*$ Including reliquefaction power of 5W and assumed propulsion power of 30MW. \\
$* *$ Combined cycle. \\
$* * *$ Typical values
\end{tabular}

\section{KEUNTUNGAN PROPULSION HYBRID}

Keuntungan yang diperoleh dari sistem propulsi hybrid adalah terdapatnya pengurangan pemakaian bahan bakar dan pemanfaatan energi yang dihasilkan semaksimal mungkin. Gambar.7 berikut merupakan hasil investigasi yang dilakukan pada kapal tanker dan cargo yang dikembangkan oleh IHI Marine United Inc, menggunakan sistem propulsi diesel-electric.

Terdapat pengurangan pemakaian bahan bakar hingga $10 \%$ per ton-kilometer muatan yang di transfer.

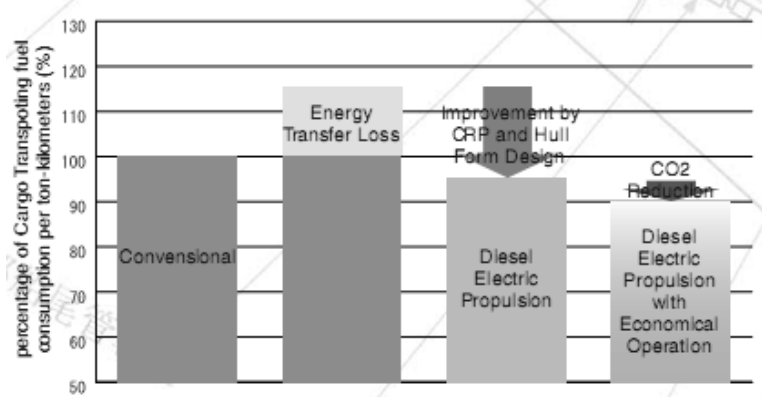

Gambar 7. Penghematan pada sistem propulsi diesel engine - electric motor

Pada sistem propulsi diesel-electric ini pemakaian ruang mesin (engine room) dapat diminimalkan, seperti yang terlihat pada gambar 8 . 


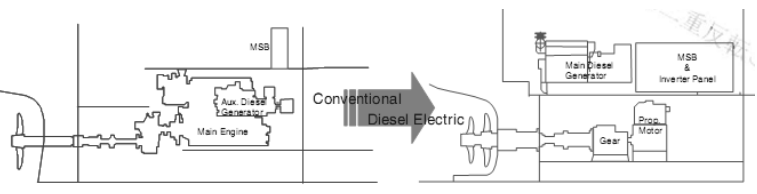

Gambar 8. Engine room arrangement

Pengurangan ruang kamar mesin menyebabkan ruang muat bertambah. Sehingga diperoleh keuntungan selama kapal dioperasional kan.

\section{KONSEP OPTIMUM PADA PEMILIHAN SISTEM PROPULSI HYBRID}

Pada penelitian sebelumnya ditemukan bahwa losses yang dihasilkan oleh motor diesel (DM) adalah $50 \%$, namun al ini sangat tergantung pada kondisi operasional (load dan RPM). Sedapat mungkin motor induk ini harus dioerasionalkan pada kondisi optimum dengan spesifik konsumsi bahan bakar seminimal mungkin. Namun selama kapal beroperasi kondisi kerja motor induk sangat bervariatif, sehingga konsumsi bahan bakar yang ekonomis ini tidak stabil, atau frekwunsinya sangat kecil.

Salah satu contoh variatif konsumsi bahan bakar motor diesel dapat dilihat dalam tabel.2 berikut : pada kondisi 85\% rpm/load konsumsi bahan bakar $188 \mathrm{~g} / \mathrm{kWh}$. Pemakaian tenaga mein 75\%, konsumsi bahan bakarnya 189 g/kWh, pada pemakaian tenga mesin 50\% lebih tinggi konsumsi bahan bakarnya yaitu $194 \mathrm{~g} / \mathrm{kWh}$, dan pada 25\% tenaga mesin konsumsi bahan bakarnya 205 g/kWh.

Tabel.2. Variatif konsumsi bahan bakar motor diesel

\begin{tabular}{|c|c|c|c|c|c|}
\hline & \multicolumn{5}{|c|}{ 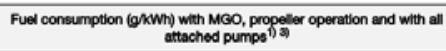 } \\
\hline & \multicolumn{5}{|c|}{ V2a/330 } \\
\hline \% Load & $100^{2}$ & 85 & 75 & 50 & 25 \\
\hline 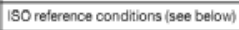 & $191.5^{21}$ & 188 & 189 & 194 & 205 \\
\hline $\begin{array}{l}\text { 1) Tolerance tor warranty }+5 \% \text {. } \\
\text { 2) Warranted fuel consumption at } 100 \\
\text { 3) Attached pumps: } H T \text {, LT and LO Du }\end{array}$ & & & & & \\
\hline
\end{tabular}

Sumber : MAN, project guide

Kondisi operasional yang konstan diperoleh dari diesel engine (DE) yang digunakan sebagai generator listrik. Namun, pemakaian diesel electric propulsi saja menyebabkan losses jauh lebih tinggi, terutama pada generators, switchboards, transformers, converters and electric motors lebih kurang 10\%.

Dengan mengkobinasi pemakaian DM dan DE (Hybrid System) diperoleh penurunan losses yaitu 5\% pada DE dan 3\% pada DM (Wartsila Low Loss Concept), seperti yang terlihat dalam gambar 9.

Losses di propulsi banyak dipengaruhi oleh beberapa faktor terutama : ukuran dan jenis propulsor, interaksi antara hull dan motor penggerak, propeller yang optimal (rpm propeller yang tinggi dan pitch rendah menyebabkan losse propulsi tinggi). Gambar.10 dibawah ini mengambarkan beberapa tahap losses power yang terjadi mulai dari sumber tenaga sampai ke daya dorong yang dapat secara efektif digunakan untuk menggerakan kapal saat berlayar. Wärtsilä LLC

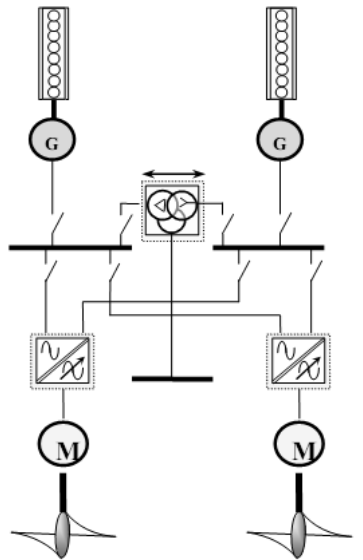

Gambar 9. Wartsila hybrid system.

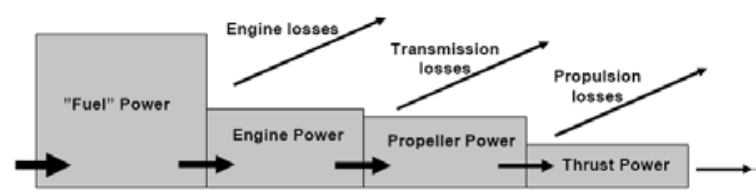

Gambar 10. Loses pada propulsi kapal

Efektifitas pemakaian tenaga mesin merupakan tolak ukur dalam penghematan bahan bakar. Jika selama periode 5 tahun, penghematan bahan bakar untuk tiap satu g/kWh akan mencapai 7,2 ton (dimana ; 5 tahun x 300 hr x 24 jam x 200 $\mathrm{kW})$.

\section{KONDISI PROPULSI KAPAL IKAN PURSEIN 30 - 90 GT}

Sistem propulsi kapal ikan tradisional di Indoesia pada umumnya menggunakan Motor Diesel bekas. Motor ini diimpor dari beberapa negara yang telah menerapkan peraturan sangat ketat pada kendaraan bermotor, terutama untuk alasan ekonomis dan dampak lingkungan yang ditimbulkan dari efek rumah kaca akibat pembakaran bahan bakar pada kendaraan tersebut.

Kemudian propeller yang dipakai diambil yang sudah ada dipasaran dan dipasang dikapal tanpa ada pertimbangan faktor effisiensi propulsi dan interaksinya dengan badan kapal (ship hull).

Kondisi ini menyebabkan pemakaian tenaga tidak optimum, dan menimbulkan pemborosan bahan bakar. Hal ini dapat dilihat dari data pada tabel 3. 
Tabel.3. Data Utama 6 (enam) kapal ikan Pekalongan yang disurvey.

\begin{tabular}{|c|c|c|c|c|c|c|c|c|c|}
\hline \multirow[b]{2}{*}{ No. } & \multirow[b]{2}{*}{ Nama Kapal } & \multirow[b]{2}{*}{$\begin{array}{c}\text { GT } \\
\text { (ton } \\
\text { nages) }\end{array}$} & \multicolumn{3}{|c|}{ main dimension } & \multicolumn{2}{|c|}{ Mesin } & \multirow{2}{*}{$\begin{array}{c}\text { Kecepatan } \\
\text { service } \\
\text { (knots) }\end{array}$} & \multirow[b]{2}{*}{$\begin{array}{l}\text { Trip } \\
\text { (hari) }\end{array}$} \\
\hline & & & $\begin{array}{c}\mathbf{L} \\
(\mathbf{m})\end{array}$ & $\begin{array}{c}\text { B } \\
(\mathbf{m})\end{array}$ & $\begin{array}{c}D \\
(\mathrm{~m})\end{array}$ & $\begin{array}{c}\text { Induk } \\
\text { (PK) }\end{array}$ & $\begin{array}{r}\text { Genset } \\
(\mathbf{k W})\end{array}$ & & \\
\hline 1 & 2 & 3 & 4 & 5 & 6 & 7 & 8 & 9 & 11 \\
\hline 1 & Modern & 30 & 18.03 & 6.35 & 2.00 & 300 & 30 & 6.00 & 100 \\
\hline 2 & Cherly Prima Utama & 61 & 22.71 & 6.65 & 2.10 & 300 & 30 & 6.00 & 110 \\
\hline 3 & Yuie Jaya & 71 & 21.46 & 6.91 & 2.20 & 300 & 30 & 6.00 & 110 \\
\hline 4 & Bintang Mas Berlian & 80 & 23.18 & 6.85 & 2.11 & 300 & 30 & 6.00 & 93 \\
\hline 5 & Baruna Batara Sakti & 91 & 23.96 & 7.02 & 2.30 & 300 & 30 & 6.00 & 110 \\
\hline 6 & Bintang Rejeki & 101 & 26.38 & 7.70 & 2.49 & 300 & 30 & 6.00 & 103 \\
\hline
\end{tabular}

Sumber : data primer, PPN, Pekalongan

Tabel.4.. Kebutuhan Daya

\begin{tabular}{cccccccc}
\hline \multicolumn{2}{c}{$\begin{array}{c}\text { Kecepatan } \\
\text { (Vs) }\end{array}$} & \multicolumn{7}{c}{ Kebutuhan Daya Mesin Induk (BHP) } \\
\cline { 3 - 7 } \% & knots & $\begin{array}{c}\text { Modern } \\
\text { GT 30 }\end{array}$ & $\begin{array}{c}\text { CP Utama } \\
\text { GT 61 }\end{array}$ & $\begin{array}{c}\text { Yuiee Jaya } \\
\text { Gt 71 }\end{array}$ & $\begin{array}{c}\text { Bintang M B } \\
\text { GT 81 }\end{array}$ & $\begin{array}{c}\text { BB Sakti } \\
\text { GT 90 }\end{array}$ & $\begin{array}{c}\text { B Rejeki } \\
\text { GT 101 }\end{array}$ \\
\hline 90 & 5.40 & 112.11 & 159.84 & 171.64 & 187.61 & 199.96 & 205.59 \\
100 & 6.00 & 124.56 & 177.60 & 190.71 & 208.46 & 222.18 & 228.43 \\
110 & 6.60 & 137.02 & 195.36 & 209.78 & 229.30 & 244.40 & 251.28 \\
120 & 7.20 & 149.48 & 213.12 & 228.85 & 250.15 & 266.62 & 274.12 \\
130 & 7.80 & 161.93 & 230.88 & 247.92 & 270.99 & 288.83 & 296.96 \\
140 & 8.40 & 174.39 & 248.64 & 266.99 & 291.84 & 311.05 & 319.81 \\
150 & 9.00 & 186.85 & 266.40 & 286.06 & 312.69 & 333.27 & 342.65 \\
160 & 9.60 & 199.30 & 284.16 & 305.13 & 333.53 & 355.49 & 365.49 \\
170 & 10.20 & 211.76 & 301.92 & 324.20 & 354.38 & 377.71 & 388.34 \\
180 & 10.80 & 224.21 & 319.69 & 343.27 & 375.22 & 399.92 & 411.18 \\
190 & 11.40 & 236.67 & 337.45 & 362.34 & 396.07 & 422.14 & 434.02 \\
200 & 12.00 & 249.13 & 355.21 & 381.41 & 416.91 & 444.36 & 456.87 \\
\hline
\end{tabular}

Sumber. Olahan data,2009

Pada tabel 3. di atas terlihat bahwa power motor induk yang digunakan sama untuk ukuran kapal yang berbeda, sehingga satu sisi kelebihan daya dan disisi lain kekurangan daya saat kapal dioperasikan.

Hasil penelitian kebutuhan daya masingmasing kapal diatas dapat dilihat dari tabel.4. berikut. Perhitungan kebutuhan daya mesin induk untuk 6 (enam) kapal ikan purse seine di Pekalongan dari hasil survey 2009, berdasarkan teori teknik perkapalan.

Power (daya) yang dibutuhkan untuk kapal 30 GT, adalah 124.56 HP untuk kecepatan kapal 6 knots (rata-rata kecepatan maksimum yang dapat dicapai oleh kapal purse seine Pekalongan), sehingga ketersediaan power di kapal hingga 300 HP dapat dimanfaatkan untuk menambah kecepatan kapal, dan kebutuhan lain seperti : power untuk mesin penarik jaring atau dapat juga di pakai sebagai pembangkit listrik untuk lampu penerangan.

Hal ini menjadi salah alasan untuk menerapkan sistem propulsi hybrid pada kapal ikan, agar pemakaian daya motor dapat optimum.

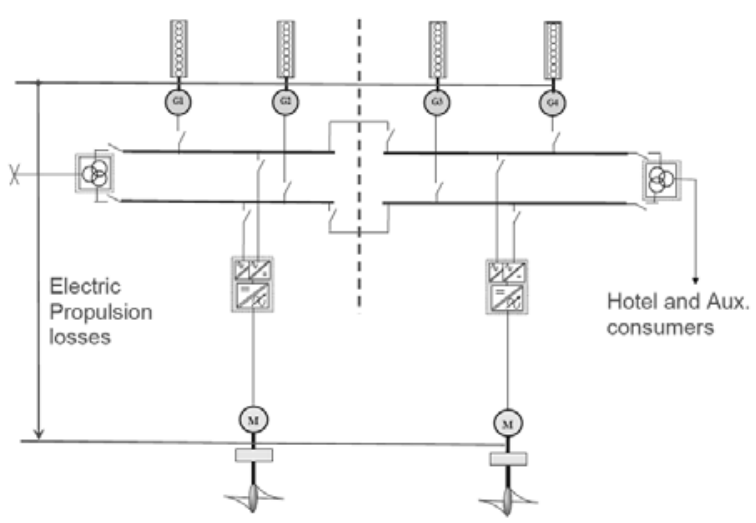

Sistem hybrid yang digunakan adalah motor diesel (genset) dengan dimensi lebih kecil dan jumlah 4 unit (masing-masing 75 HP) dan motor elektrik untuk penggerak kapal. Pengoperasian motor diesel dapat di atur sesuai dengan kebutuhan dan kondisi operasional kapal ikan.

Hasil perhitungan untuk variabel kecepatan dinas saja, daya motor yang terpakai adalah $83 \%$ sebanyak dua unit, sehingga penghematan konsumsi bahan bakar rata-rata 6 g/k W h (2,5 \%). Jumlah konsumsi bahan bakar awal adalah 609 
kg/24 jam, dengan hanya menggunakan dua unit motor dengan kondisi load $85 \%$ adalah 507 kg/ 24 jam, sehingga penghematan cost operasional dari bahan bakar saja adalan 16,74\%.

\section{DAFTAR PUSTAKA}

1. Rune Lysebo, Jan Fredrik Hansen, Comparison Of Electric Power And Propulsion Plants For Lng Carriers With Different Propulsion Systems ABB AS, Oslo, Norway,www.abb.com/marine.

2. R Courtay, L Claes and J Sainson, 2004, LNG Carriers Using Gas Fuel Only, Diesel Gas Electric Propulsion, Proc. of the 14th International Conference \& Exhibition on Liquefied Natural Gas, Doha.
3. J. F. Hansen, R. Lysebo, 2004, Electric propulsion for LNG carriers. LNG Journal.

4. J. F. Hansen, R. Lysebo, 2006, HV Electric Power And Propulsion Solutions For New Generation Of LNG Carriers With Various Propulsion Systems. Proc. of the $28^{\text {th }}$ Annual Event "The Motor Ship Propulsion Conference”, Copenhagen.

5. B. Thijssen, 2006, Dual-Fuel-Electric LNG carriers., Proc. of the $28^{\text {th }}$ Annual Event "The Motor Ship Propulsion Conference”, Copenhagen.

6. IHI Marine United Inc,Contra-rotating Propulsion Fitted Diesel Electric Propulsion Vessel Contra-rotating Propulsion Fitted Diesel Electric Propulsion Vessel, www.ihi.co.jp. 